\title{
Pandemia da COVID-19 e Teletrabalho: os Principais Direitos e Desafios
}

\author{
Covid-19 Pandemic and Teleworking: the Main Rights and Challenges
}

\author{
Mickael Ferreira Alves
}

Faculdade Pitágoras de Belo Jardim, Curso de Direito. PE, Brasil.

E-mail: mickael.alves@kroton.com.br

\begin{abstract}
Resumo
No final do ano de 2019 e início do ano de 2020, o Mundo presenciou uma das maiores crises da história, com a propagação do vírus da COVID-19. Impondo o isolamento social como a principal estratégia de prevenção, a Pandemia impacta a vida humana em todos os seus aspectos, entre esses a forma do trabalho, tendo grande destaque a difusão do teletrabalho ou home office. Dessa forma, diante da implantação urgente dessa modalidade de regime de trabalho, as empresas, os gestores e os próprios trabalhadores estão sendo desafiados a encontrar a medida adequada da distribuição e execução de metas e de prazos que concorrem com o tempo do convívio familiar, tarefas domésticas e atividades escolares. Com isso, em função do avanço da Pandemia do novo coronavírus no Brasil e no Mundo, muitas empresas se viram obrigadas a implementar o sistema teletrabalho para seus funcionários. O estudo se caracterizou por ser uma pesquisa bibliográfica, de caráter exploratório, realizada por meio de livros, leis, códigos e artigos científicos. Diante desse cenário de crise, o presente trabalho buscou explicar quais são os direitos, segundo as leis trabalhistas e segundo a Lei $\mathbf{n}^{\mathbf{0}}$ 13.979/2020, que trata especificamente sobre o COVID-19 em relação ao teletrabalho.
\end{abstract}

Palavras-chave: Crise. COVID-19. Isolamento. Teletrabalho.

\begin{abstract}
At the end of 2019 and the beginning of 2020, the world witnessed one of the greatest crises in history, with the spread of the Covid-19 virus. Imposing social isolation as the main prevention strategy, the pandemic impacts human life in all its aspects, among them the form of work, with great emphasis on the diffusion of telework or home office. Thus, due to the urgent implementation of this type of work regime, companies, managers and the workers themselves are being challenged to find the appropriate measure for the distribution and execution of goals and deadlines that compete with family time, housework and school activities. Thus, due to the advance of the new coronavirus pandemic in Brazil and worldwide, many companies were forced to implement the telework system for their employees. The study was characterized by being an exploratory bibliographic research, carried out through books, laws, codes and scientific articles. Faced with this crisis scenario, the present work sought to explain what the rights are, according to labor laws and according to Law 13.979/2020, which specifically deals with Covid-19 in relation to teleworking.
\end{abstract}

Keywords: Crisis. Covid-19. Isolation. Teleworking.

\section{Introdução}

Historicamente, o teletrabalho cresceu no colapso, assim foi na década de 1970 quando Jack Nilles propôs inverter a operação, deslocando o trabalho para casa diante da crise do petróleo, ou mesmo o elevado desenvolvimento nos Estados Unidos da América após os atentados de 11 de setembro (OLIVEIRA NETO, 2020).

No Brasil, 45\% das empresas já adotavam o teletrabalho antes da COVID-19 ${ }^{1}$, representando contingente de mais de 15 milhões de teletrabalhadores. Sem pré-aviso, de supetão, 4 bilhões de pessoas foram colocadas em alguma espécie de isolamento social.

Na canção intitulada "O dia em que a Terra parou", de autoria do falecido cantor Raul Seixas, percebe-se na referida canção que o empregado não saiu para o seu trabalho, inclusive que seu patrão não estaria na empresa, ou seja, ali de certa forma iniciaria uma possível relação de teletrabalho.

Antes de se continuar com o presente estudo, é importante destacar as principais diferenças entre teletrabalho e home office. No teletrabalho, a própria Consolidação das Leis Trabalhistas (CLT), em seu artigo 75-B, diz que a prestação de serviços, preponderantemente, fora das dependências do empregador, com utilização de tecnologias de informação e comunicação que, por sua natureza, não se constituam como trabalho externo (Incluído pela Lei no 13.467, de 2017).

Dessa forma, a prestação do serviço em caráter de teletrabalho pode ocorrer em qualquer lugar, sendo preponderantemente fornecido fora das dependências 
do empregador, podendo ser prestado na residência do empregado.

Por sua vez, o home office se caracteriza quando o trabalho é realizado remotamente de maneira eventual na residência do empregado, podendo ou não configurar a hipótese de teletrabalho, sendo benéfico, principalmente, em casos de emergências como Pandemias, enchentes e greves. Nem todas as atividades em home office se utilizam da tecnologia, que é condição preponderante para caracterização do teletrabalho.

No home office pode existir uma flexibilização no regime de trabalho presencial, em que o empregado pode prestar o serviço alguns dias em sua residência remotamente. Não precisa constar em contrato individual de trabalho ou aditivo contratual, devendo ser regulado por política interna da empresa.

Após esses conceitos iniciais, pode-se dizer que a intensificação do teletrabalho durante a Pandemia COVID-19 vem acompanhada de grandes dificuldades e desafios, tanto para as empresas quanto para os trabalhadores e familiares. As empresas tiveram de estabelecer políticas e normas internas para implementar e assegurar o teletrabalho. A segurança da informação teve que ser revista para incorporar a rotina de trabalho remoto. Recursos foram investidos para possibilitar acesso a equipamentos e ferramentas de comunicação remota.

Para os trabalhadores surgiram desafios como a necessidade do rápido aprendizado de novas tecnologias, o estabelecimento de novas formas de interação e comunicação entre as equipes. Suas vidas familiares tiveram de ser conciliadas com o trabalho. Para muitos, a vida pública e a privada nunca esteve tão entrelaçada. Famílias passaram a dividir em um mesmo ambiente as atividades de trabalho, escolares, domésticas e de lazer (LOSEKANN; MOURÃO, 2020).

O controle do tempo e do esforço de trabalho é um desafio usual na relação de empresas e trabalhadores. A combinação de controle de frequência e estabelecimento de metas visam alinhar os interesses nessa relação e a motivação do trabalhador deve ser um objeto fundamental da gestão de pessoas. Em regime de teletrabalho, esse desafio é intensificado.

Com isso, a adoção do teletrabalho aos empregados tem a finalidade de restringir o contato social em meio à crise pandêmica. O intuito é a preservação da saúde e da vida da classe trabalhadora nacional. Instaurado em função do estado de calamidade, o teletrabalho foi regulamentado pela MP 927/2020, que estabeleceu mudanças na legislação trabalhista vigente, e está previsto na CLT, no artigo 62, inciso III, além dos artigos 75-A a 75-E.

Com tristeza se depara com a impossibilidade de usufruir dos prazeres da vida moderna: cinemas, teatros, casas de shows, clubes, academias de ginástica, bares, restaurantes e shoppings. Viagens, casamentos, churrascos, batizados e eventos profissionais adiados, sem que se tenha ao menos a noção de quando a vida a que se estava acostumado retomará o seu curso.

Confinados, as pessoas estão a viver duas vidas dentro das casas: uma intensa e interna, pessoal e familiar, e outra de relacionamentos sociais e profissionais, que estão a invadir a vida privada sem noção de horário, dia útil ou feriado, para possibilitar as interações sem as quais se perde a noção do papel social na sociedade.

Diante dessa realidade, as Medidas Provisórias 927/2020 e 936/2020 surgiram como tábuas de salvação contra o risco do desemprego. Entre dois bens jurídicos, a proteção social plena e o desemprego são proporcionalmente melhores ter férias cumulativamente antecipadas; trabalhar remotamente; laborar em jornada reduzida, com redução salarial proporcional; ou receber compensação pela suspensão do contrato com base no valor do seguro-desemprego do que ficar no olho da rua.

A partir dessas premissas se tem o seguinte problema de pesquisa: quais os principais direitos e desafios no teletrabalho em virtude da Pandemia da COVID-19?

E com isso os objetivos da presente pesquisa foram descrever os principais direitos no teletrabalho; os principais desafios no teletrabalho na pandemia da covid-19; e apontar as principais consequências da Pandemia da COVID-19 no teletrabalho.

\section{Desenvolvimento}

\subsection{Metodologia}

Caracterizando o estudo, em relação aos métodos científicos quanto à abordagem ocorreu pelo método dedutivo, tendo em vista a generalização, ou seja, partiu de algo particular para uma questão mais ampla, mais geral.

Com relação aos procedimentos, o presente trabalho ocorreu em comparativo e se ocupou da explicação dos fenômenos, permitindo analisar o dado concreto, deduzindo desse os elementos constantes, abstratos e gerais.

$\mathrm{E}$ com relação à pesquisa em si quanto a natureza, percebeu-se como sendo aplicada, porque objetivou gerar conhecimentos para aplicação prática dirigidos à solução de problemas específicos relacionados às questões dos direitos e desafios do teletrabalho.

Já do ponto de vista de seus objetivos, a pesquisa se realizou como exploratória e explicativa em função do uso de material bibliográfico através de material já publicado em fontes oficiais como o Senado Federal, Câmara dos Deputados Federais e Tribunais Superiores, o que explica também em dizer ser a pesquisa, quantos aos procedimentos, como sendo bibliográfica.

E por último, quanto à forma de abordagem, a pesquisa ocorreu como qualitativa, tendo em vista seu objetivo de investigação abordar a compreensão com a descrição e geração de hipóteses relacionadas aos constructos sobre teletrabalho. 


\subsection{Principais Direitos dos Trabalhadores Brasileiros no Contexto da COVID-19}

O Coronavírus (COVID-19) impacta o Mundo inteiro. No dia 11 de março, a Organização Mundial de Saúde (OMS) declarou que já se tratava de uma Pandemia. Afinal, a lista de países afetados, de casos positivos e de casos suspeitos cresce a cada dia. Inclusive, no Brasil. $\mathrm{O}$ isolamento social, ainda segundo a OMS, é a melhor forma de controlar a propagação dessa virose. Com isso, o teletrabalho eventual (trabalho remoto ou home office) passou a ser incentivado em todo o Mundo. No entanto, no país, ainda há empresas que não liberam os seus colaboradores, mesmo aqueles que se incluem no grupo de risco.

Diante desse cenário de crise, explica-se quais são os principais direitos, segundo as leis trabalhistas e segundo a Lei $\mathrm{n}^{\circ}$ 13.979/2020, que trata especificamente sobre o COVID-19.

Com relação ao teletrabalho, a Reforma Trabalhista de 2017 formalizou essa modalidade, caracterizando o teletrabalho como "a prestação de serviços preponderantemente feita fora das dependências do empregador" (art. 75-B da Consolidação das Leis do Trabalho - CLT), conforme já mencionado.

De origem etimológica grega, tele significa distância. $\mathrm{O}$ teletrabalho é modalidade especial de trabalho a distância, tipo específico, contido neste. Não à toa, o legislador reformista o colocou com requisitos específicos e formalidades intrínsecas à contratação, que o faz um contrato de tipo especial.

No teletrabalho são conjugados elementos que permitem identificar algo além do mero trabalho fora do estabelecimento (sede física) do empregador. Tem-se a presença obrigatória da tecnologia da comunicação e informação, quer como ferramenta de trabalho, quer como mediadora da distância relacional, ou até como próprio espaço (virtual) de trabalho (BELMONTE; MARTINEZ; MARANHÃO, 2020).

O teletrabalho não afasta a relação subordinada, como se desconfiava nos primórdios de seus estudos. A questão, aliás, foi resolvida legislativamente no Brasil ainda em 2011, com a alteração do artigo $6^{\circ}$ da CLT, que admitiu mesma eficácia presencial ao comando, supervisão e controle de exercidos de forma telemática, não sem antes igualar o trabalho presencial ao trabalho a distância (gênero do qual o teletrabalho faz parte). Tal igualização legal-formal, no entanto, não satisfazia as peculiaridades da modalidade laboral específica, de modo que o meio produtivo seguia reclamando melhores definições legais e, enquanto tais não vinham, apostava em políticas (regulamentos) empresariais e instrumentos coletivos para supressão da lacuna legal (BELMONTE; MARTINEZ; MARANHÃO, 2020).

Com isso, antes dessa reforma, no entanto, a CLT já abordava o teletrabalho. Em seu artigo $6^{\circ}$, estabelece que "não se distingue entre o trabalho realizado no estabelecimento do empregador, o executado no domicílio do empregado e o realizado à distância”. O requisito, segundo o mesmo artigo, é de que "estejam caracterizados os pressupostos da relação de emprego". Em outras palavras, os direitos do trabalhador com CLT são os mesmos no regime de teletrabalho, segundo a legislação trabalhista.

O trabalho remoto - ou home office - em tempos de Coronavírus tem a particularidade de ser algo eventual. Isto é, o trabalhador que não exerce previamente essa modalidade de prestação de serviço passará a trabalhar fora dos limites da empresa.

Muitas organizações, incluindo o BNDES e outros bancos, já adotaram o home office nesse período de crise mundial. Para muitos, há uma questão de bom senso envolvida nessa decisão. Afinal, na cartilha divulgada pela OMS, o isolamento social aparece como uma das ações-chave para controlar a pandemia.

Outro ponto importante nessa discussão de direitos trabalhistas se refere ao cumprimento da quarentena, ou seja, o isolamento social por, pelo menos, 14 dias - consta na Lei ${ }^{\circ}$ 13.979/2020, sancionada pelo Governo Federal em fevereiro deste ano, que trata especificamente sobre medidas contra o Coronavírus no Brasil.

Pessoas que viajaram para o exterior ou que tiveram contato direto com quem viajou devem cumprir o isolamento social. O período de ausência no trabalho em função da quarentena será considerado falta justificada. Com o devido atestado médico, o trabalhador não pode ser penalizado pelos 15 dias de ausência. E a empresa deve arcar com o pagamento integral por esses dias.

Para comprovar a obrigatoriedade de realizar a quarentena, o trabalhador deve apresentar para a equipe de $\mathrm{RH}$ da sua empresa, cópia do seu passaporte. Assim, confirma que esteve em áreas afetadas e que, em razão disso, deve cumprir com o período de isolamento social, mesmo se não apresentar nenhum sintoma vinculado à virose.

Outra discussão importante se refere aos trabalhadores em grupo de risco, tais como: idosos acima de 65 anos, grávidas e lactantes, pessoas com histórico de doenças pulmonares, pacientes com histórico de doenças, como diabetes, hipertensão e AIDS e pacientes em tratamento ou póstratamento de câncer. Para os trabalhadores que se enquadram em uma das situações acima, o isolamento social deve ser ainda mais rigoroso, já que a taxa de mortalidade da virose tende a ser maior em pacientes nesses contextos.

É importante frisar que o empregador deverá garantir o fornecimento de todas as ferramentas necessárias para que o colaborador possa desenvolver suas atividades laborais de casa, assim como faria na empresa. É preciso que ele tenha todos os materiais necessários à disposição, como computador, celular, internet, entre outros. A garantia de equipamentos ergonômicos para a preservação da saúde ocupacional do trabalhador também é um dever das empresas. O empregador ainda deverá garantir o uso correto dos equipamentos fornecidos para seus empregados, caso contrário, eventuais problemas decorrentes das atividades exercidas, mesmo que "in home", poderão refletir em responsabilização do 
empregador (SIMÕES, 2020).

Evidente que o empregador não poderá ir pessoalmente fazer uma fiscalização. Por isso, existem maneiras mais simples de garantia, como exemplo: fornecimento de cartilhas instrutivas com orientações ergonômicas ou com sugestões de adequações dos postos de trabalho; elaboração de programas de ginástica laboral, com cronograma de pausas; controle de jornada, com registro dos intervalos; agendamento de reuniões online para verificação das estações de trabalho; oferecimento de treinamentos de saúde e segurança, que também poderão ser realizados na modalidade online.

Além disso, é preciso ressaltar que no regime de teletrabalho o controle de jornada é dispensável, portanto, não há pagamento de horas extras e adicional noturno. Isso porque o empregado possui liberdade para desenvolver seus afazeres.

Por outro lado, o home office constitui modalidade de trabalho a distância, executada na residência do empregado, de forma eventual, não possui disposição expressa na CLT, deve ser instituído em norma interna da empresa e não exige formalização no contrato de trabalho (PACHECO, 2020).

Nesses casos, o empregado não cumprirá sua jornada, preponderantemente, fora das dependências do empregador. $\mathrm{O}$ exercício de suas funções poderá ser realizado de casa em determinados dias da semana ou períodos, de modo que poderá, inclusive, prestar o serviço parte em sua residência, parte no estabelecimento do empregador.

Uma das grandes preocupações com o trabalho remoto é a questão do controle da boa ambiência laboral, que deve seguir ditames de equilíbrio e de salubridade idênticos ao espaço presencial, atribuindo o Judiciário tal responsabilidade ao empregador, tradicionalmente. Nesta perspectiva, já existe julgado do Tribunal Regional da $3^{\text {a }}$ Região (Minas Gerais) acerca de demanda que envolveu trabalho em domicílio e doença ocupacional (não propriamente teletrabalho, sendo o paradigma válido para fins didáticos). Destarte, percebe-se que o legislador reformista segue a lógica da CLT, que no artigo 157 determina que o empregador instrua seus empregados acerca dos riscos do trabalho e do ambiente de labor, educando-os para a precaução (BELMONTE; MARTINEZ; MARANHÃO, 2020).

\subsection{Principais Desafios dos Trabalhadores Brasileiros no Contexto da COVID-19}

Com relação aos desafios desse novo regime de trabalho, para que parte dos desafios sejam superados se deve iniciar pela implementação de um programa de teletrabalho estruturado, cuja partida ocorre com a elaboração da relação dos elegíveis, considerados o tipo de trabalho executado e os meios tecnológicos necessários e disponíveis.

Nessa esteira, recomendável pensar em um projeto estruturado de teletrabalho que contemple minimamente as seguintes etapas: 1) criação de um comitê de implementação e gestão; 2) diagnóstico dos processos e tecnologias organizacionais; 3) criação de políticas de teletrabalho; 4) criação de políticas de segurança da informação; 5) capacitação e treinamento dos envolvidos; 6) início de projeto piloto.

Mesmo assim, grande parte dos Tribunais pátrios, no entanto, em seus regimentos internos, permite o teletrabalho, condicionando o servidor a arcar com os custos e manutenção dos equipamentos, mediante produtividade superior. O próprio Tribunal Superior do Trabalho (TST) disciplina, por meio da Resolução $n^{0} 1499$, que o servidor arque com os custos de instalação e manutenção de equipamentos necessários ao desempenho da função, mediante produtividade, no mínimo, $15 \%$ superior à presencial, veja-se:

Art. $7^{\circ}$ Compete exclusivamente ao servidor providenciar as estruturas físicas e tecnológica necessárias à realização do teletrabalho, mediante uso de equipamentos ergonômicos e adequados. Parágrafo único. O servidor, antes do início do teletrabalho, assinará declaração expressa de que a instalação em que executará o trabalho atende às exigências do caput, se necessário, solicitar a avaliação técnica do Tribunal.

A título meramente exemplificativo, o TJPE exige produtividade $30 \%$ superior e o TRF4 fixa o percentual de $10 \%$ acima, se comparado ao regime presencial.

Alguns dados interessantes dizem que a maior produtividade tem sido observada por corporações e organizações diversas. A título exemplificativo, a Agência Nacional de Energia Elétrica percebeu que a área que cuida de Pesquisa e Desenvolvimento analisou 210\% mais projetos do que em igual período de 2019 , e $111 \%$ mais projetos de Eficiência Energética².

Trata-se de novo paradigma, conectado aos resultados, tal como prevê o art. $1^{\circ}$ da Resolução $n^{\circ} 6770$ do STF, que estabelece "modelo diferenciado de gestão de atividades voltado para a entrega de resultados nos trabalhos realizados nos formatos presencial e à distância.".

E por último se pode dizer que a preocupação do gestor deve ser com o resultado, muitas vezes revelado pelo cumprimento de metas, de planejamento ou projeto entabulado, e não de controle sobre o tempo, que passa a ser do teletrabalhador, a quem cabe gerenciar os horários de trabalho e os momentos de aproximação com o núcleo familiar, ou mesmo o desenvolvimento de outras atividades extra laborais, tudo de acordo com o seu ritmo. Gestores ainda estão descobrindo a medida certa da distribuição de tarefas, evitando, por ensaio e erro, os extremos da sobrecarga e do afrouxamento de metas. A definição de metas factíveis deve ser uma condição para o sucesso desse regime, promovendo a produtividade e a inovação e preservando a saúde mental e o bem-estar de todos os trabalhadores (LOSEKANN; MOURÃO, 2020).

Essas reflexões são muito relevantes para o período atual de isolamento, mas certamente serão úteis posteriormente, pois o teletrabalho deve ocupar papel mais relevante do que 
no período anterior à Pandemia. A adaptação das rotinas de gestão de incorporação do teletrabalho deve evoluir com o aprendizado desse período inusitado.

\section{Conclusão}

Em um contexto fático de Pandemia Mundial, as modalidades de trabalho a distância em virtude da impossibilidade de aglomeração são ótimas alternativas para contornar os efeitos econômicos e sociais. Diante de todo exposto, é de fundamental importância compreender os institutos e alternativas de trabalho à distância, seja para o empregado e para o empregador, de forma a minorar riscos e prejuízos futuros neste ambiente de incertezas.

Do ponto de vista do empregador, essencial que se observe o quanto disposto legalmente para não incorrer em excessos, gerando um eventual risco de descaracterização do regime de teletrabalho futuramente.

A Pandemia da COVID-19 agravou as condições precárias de trabalho, já em curso, e acentuou a exploração dos trabalhadores a partir de novas configurações, como o home office, a transformação do lar em ambiente de trabalho, a intensificação e flexibilização das jornadas e a perda de benefícios como o vale alimentação. No que se refere ao ponto de vista do empregado, importante que o mesmo entenda como funciona o regime de trabalho e os direitos inerentes a esse, para que possa ter uma rotina de trabalho sustentável e de forma a minorar os riscos de violação de seus direitos.

Como principal limitação da pesquisa se aponta a influência do recorte temporal nos resultados, em função do momento de incerteza e transformações muito velozes da realidade trazidos pela Pandemia da COVID-19. Por exemplo, no Estado de Pernambuco foi determinada quarentena oficial já há algumas semanas com retorno previsto no início de abril de 2021 para diversas atividades, tais como comércio, indústrias e, principalmente, o setor de Educação.

Assim, o objetivo deste trabalho foi descrever os principais direitos e desafios ao enfrentamento da Pandemia da COVID-19 através de instituto do teletrabalho, como sendo uma alternativa nas relações trabalhistas.
Com tudo, se conclui que o estabelecimento do home office se tornou uma importante ferramenta na prevenção do coronavírus. Se bem implementado e administrado, o modelo poderá resguardar a saúde e a vida tanto dos empregados quanto dos empregadores.

\section{Referências}

BELMONTE, A.A.; MARTINEZ, L.; MARANHÃO, N. $O$ Direito do Trabalho na crise da COVID-19. Salvador: JusPodivm, 2020.

CORONAVÍRUS e Teletrabalho: você sabe quais são os seus direitos? Âmbito Jurídico. 2020. Disponível em: <https:// ambitojuridico.com.br/modelos-e-pecas/coronavirusteletrabalho-direitos/> Acesso em: 27 ago. 2020.

FILARDI, F.; CASTRO, R.M.P.; ZANINI, M.T.F. Vantagens e desvantagens do teletrabalho na administração pública: análise das experiências do Serpro e da Receita Federal. Cad. EBAPE. $B R$, v. 18, n.1, p.28-46, 2020. doi: https://doi.org/10.1590/1679395174605 .

LEMOS, A.H.C.; BARBOSA, A.O.; MONZATO, P.P. Mulheres em home office durante a Pandemia da Covid-19 e as configurações do conflito trabalho-família. Rev. Adm. Empres., v.60, n.6, p.388399, 2020. doi: https://doi.org/10.1590/s0034-759020200603.

LOSEKANN, R.G.C.B.; MOURÃO, H.C. Desafios do teletrabalho na pandemia da covid-19: quando o home vira office. Cad. Adm., v.28, 2020.

OLIVEIRA NETO, C.P. Quais os principais desafios para o teletrabalho pós Covid-19? Disponível em: <https://www.jota. info/opiniao-e-analise/artigos/quais-os-principais-desafios-parao-teletrabalho-pos-covid-19-03072020\#_ftn12> Acesso em: 27 ago. 2020 .

PACHECO, A.M.G. Teletrabalho e home office: qual a diferença? 2020. Disponível em: <http://www.editoramagister.com/ doutrina_27996291_TELETRABALHO_E_HOME_OFFICE_ QUAL_A_DIFERENCA.aspx> Acesso em: 27 ago. 2020.

SILVA, I.C.M.; SILVA, M.H.; SANTOS, M.L. Condições de trabalho em casa durante a pandemia: uma análise do discurso do sujeito coletivo dos trabalhadores do setor de agências de turismo. Rev. Bras. Pesq. Tur., v.15, n.1, 2021. doi: https://doi. org/10.7784/rbtur.v15i1.2200.

SIMÕES, L.S. Covid-19 - Teletrabalho e suas implicações trabalhistas. 2020. Disponível em: <https://www.migalhas.com. br/depeso/327034/covid-19-teletrabalho-e-suas-implicacoestrabalhistas> Acesso em: 27 ago. 2020. 